\title{
Does technetium-99m diethylenetriaminepentaacetate clearance predict the clinical course of idiopathic pulmonary fibrosis?
}

\author{
Marco Mura MD¹, Gelorma Belmonte $M D^{1}$, Stefano Fanti MD², Angela Maria Grazia Pacilli MD , Luca Fasano MD , \\ Maurizio Zompatori $\mathrm{MD}^{3}$, Mario Schiavina $\mathrm{MD}^{1}$, Mario Fabbri MD ${ }^{1}$
}

\begin{abstract}
M Mura, G Belmonte, S Fanti, et al. Does technetium-99m diethylenetriaminepentaacetate clearance predict the clinical course of idiopathic pulmonary fibrosis? Can Respir J 2004;11(7):477-479.
\end{abstract}

Clearance of inhaled technetium-99m diethylenetriaminepentaacetate ( ${ }^{99} \mathrm{~m}$ Tc-DTPA) is a potential indicator of disease activity and progression in idiopathic pulmonary fibrosis (IPF). The objective of the present study was to evaluate the prognostic value of ${ }^{99 \mathrm{~m}} \mathrm{Tc}$-DTPA scans in IPF. A total of 22 patients (18 males), aged 33 to 80 years with IPF were followed for six to 20 months (mean 13 months). At diagnosis, high resolution computed tomography (HRCT) scans showed a honeycomb pattern with bibasilar reticular opacities in all cases. At T0 (diagnosis) and T1 (follow-up), each patient had pulmonary function tests (forced vital capacity, diffusing capacity of the lung for carbon monoxide and partial arterial $\mathrm{O}_{2}$ pressure), extension of fibrosis evaluated by HRCT visual score and ${ }^{99 \mathrm{~m} T c-D T P A}$ lung clearance. Results at T0 and T1 were compared, taking into account the whole population and patients with relatively fast and slow ${ }^{99 \mathrm{~m}}$ Tc-DTPA wash-out. ${ }^{99 \mathrm{~m} T \mathrm{~T}-\mathrm{DTPA}}$ clearance did not show any significant correlation with functional tests or HRCT score. These findings indicate that clearance of inhaled ${ }^{99 \mathrm{~m}} \mathrm{Tc}$-DTPA is not of value in following the progress of IPF.

Key Words: ${ }^{99 m}$ Tc-DTPA clearance; High resolution computed tomography; Idiopathic pulmonary fibrosis; Lung epithelial permeability
La clairance du technétium-99m pentétate permet-elle de prédire l'évolution clinique de la fibrose pulmonaire idiopathique?

La clairance du technétium-99m pentétate ( ${ }^{99 \mathrm{~m}} \mathrm{Tc}$-P) inhalé est un indicateur potentiel de l'activité de la maladie et de son évolution en fibrose pulmonaire idiopathique (FPI). La présente étude visait à évaluer la valeur pronostique de tomodensitométries de ${ }^{99 \mathrm{~m}} \mathrm{TC}-\mathrm{P}$ en cas de FPI. Au total, 22 patients (18 hommes) de 33 à 80 ans souffrant de FPI ont été suivis pendant six à 20 mois (moyenne de 13 mois). Au diagnostic, une tomodensitométrie à haute résolution (THR) a révélé un profil alvéolaire avec des opacités réticulaires bibasilaires dans tous les cas. Au TO (diagnostic) et au T1 (suivi), chaque patient a subi des explorations fonctionnelles respiratoires (capacité vitale forcée, capacité de diffusion pulmonaire du monoxyde de carbone et pression partielle de l'oxygène dans le sang artériel), une propagation de la fibrose évaluée par le score visuel de la THR et une clairance pulmonaire du ${ }^{99 \mathrm{~m}} \mathrm{Tc}-\mathrm{P}$. Les résultats au T0 et au T1 ont été comparés, compte tenu de l'ensemble de la population et des patients affichant une élimination relativement rapide ou lente du ${ }^{99} \mathrm{~m}$ Tc-P. La clairance du ${ }^{99 \mathrm{~m}} \mathrm{Tc}$-P n'a pas révélé de corrélation significative avec les explorations fonctionnelles respiratoires ou le score de THR Ces observations indiquent que la clairance du ${ }^{99 \mathrm{~m}} \mathrm{Tc}-\mathrm{P}$ inhalé n'est pas valable pour suivre la progression de la FPI. diopathic pulmonary fibrosis (IPF) is a chronic fibrotic pulmonary disease with poor prognosis $(1,2)$. Currently, the recommended approach to stage and predict the progression of IPF is based on pulmonary function tests (PFTs) and high resolution computed tomography (HRCT) (3-5).

Technetium-99m diethylenetriaminepentaacetate ( ${ }^{99 \mathrm{~m}} \mathrm{Tc}$-DTPA) aerosol clearance is a noninvasive index of pulmonary epithelial permeability; increased permeability results from inflammation of the lung parenchyma in a variety of diffuse lung diseases (6). Test interpretation is based on the analysis of radionuclide clearance after the isotope is administered as a soluble aerosol, with a particle diameter of less than $2 \mu \mathrm{m}$, and after cigarette smoking has been suspended for at least one week (7-9). A clearance half-time of less than $50 \mathrm{~min}$ is considered to be pathological and suggests diffuse interstitial damage $(10,11)$. Increased ${ }^{99 \mathrm{~m}} \mathrm{Tc}$-DTPA clearance has been cited as an early marker of inflammation and activity grade $(12,13)$.

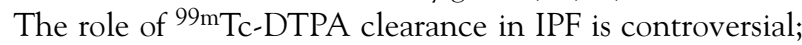
according to some authors (13), the procedure should not be recommended as a routine test in IPF, while other investigators $(14,15)$ have identified this technique as a significant predictor of clinical course and survival.

The present study was designed to evaluate the potential of ${ }^{99} \mathrm{~m}$ Tc-DTPA scans to assess disease activity and progression of IPF. To assess the usefulness of ${ }^{99 m}$ Tc-DTPA scans, we prospectively studied a group of IPF patients and compared the results of this nuclear medicine test with HRCT quantitative scanning and PFTs.

${ }^{1}$ Unita operativa Fisiopatologia Respiratoria and ${ }^{2}$ Unita operativa Medicina Nucleare, Policlinico Sant'Orsola Malpighi, Bologna;

${ }^{3}$ Unita operativa Scienze Radiologiche, Policlinico Rasori, Parma, Italy

Correspondence: Dr Marco Mura, Thoracic Surgery Research Laboratory, 200 Elizabeth Street, Max Bell Research Building,

Room 5R425, Toronto, Ontario M5G 2C4. Telephone 416-340-4400, fax 416-340-4638, e-mail mmura@uhnres.utoronto.ca 


\section{TABLE 1}

Pulmonary function studies, radiographic extent of idiopathic pulmonary fibrosis and technetium-99m diethylenetriaminepentaacetate ( ${ }^{99 \mathrm{~m} T c-D T P A}$ ) findings at diagnosis (T0) and follow-up (T1) in the whole population $(n=22)$

\begin{tabular}{|c|c|c|c|}
\hline & T0 & T1 & $\mathbf{P}$ \\
\hline \multirow[t]{2}{*}{ HRCT score (\%) } & $46.5 \pm 12.8$ & $51.8 \pm 13.4$ & 0.0013 \\
\hline & (range 20.0 to 70.0 ) & (range 28.5 to 75.0 ) & \\
\hline FVC (\% pred) & $69.8 \pm 18.6$ & $64.8 \pm 16.7$ & 0.0002 \\
\hline DLCO (\% pred) & $36.9 \pm 21.1$ & $27.7 \pm 19.9$ & 0.00003 \\
\hline $\mathrm{PaO}_{2}(\mathrm{mmHg})$ & $75.0 \pm 14.5$ & $68.7 \pm 15.2$ & 0.0011 \\
\hline $\begin{array}{l}\text { Clearance of } \\
\text { 99mTc-DTPA (min) }\end{array}$ & $29.5 \pm 11.3$ & $35.2 \pm 15.2$ & 0.033 \\
\hline
\end{tabular}

Student's t test for dependent variables. DLCO Diffusing capacity of the lung for carbon monoxide; FVC Forced vital capacity; HRCT High resolution computed tomography; $\mathrm{PaO}_{2}$ Arterial $\mathrm{O}_{2}$ pressure at rest; pred Predicted normal value

\section{METHODS}

Twenty-two patients, 18 males and four females, aged 33 to 80 years (mean $66 \pm 10.5$ years) (19 former smokers), diagnosed with IPF on the basis of American Thoracic Society/European Respiratory Society criteria (6), were studied and followed for a period of six to 20 months (mean follow-up was 13 months). HRCT scans revealed a honeycomb pattern with basal and peripheral reticular opacities, and traction bronchiectasis in all patients (16).

Patients were examined when stable, without signs of heart failure or acute inflammation, on two occasions: at presentation (T0) and at follow-up (T1). Patients had PFTs, and HRCT and ${ }^{99 \mathrm{~m}} \mathrm{Tc}$-DTPA scans. Informed consent was obtained from all patients.

During the T0 to T1 interval, nine patients were treated with corticosteroids (prednisolone $0.5 \mathrm{mg} / \mathrm{kg} /$ day for four weeks, followed by $0.25 \mathrm{mg} / \mathrm{kg} /$ day for eight weeks and then followed by $0.125 \mathrm{~g} / \mathrm{kg} /$ day for four to 12 weeks).

HRCT scans were performed with a single breath hold in the prone position (17), without intravenous injection of contrast material and using a filter for the osseous tissue. One millimetre thick sections were taken, with a $1 \mathrm{~s}$ scan time and $10 \mathrm{~mm}$ intervals between sections. Both lungs were included in the field of view. The extent of the lesions was evaluated with a visual score and expressed as a percentage of total lung volume, as previously described (18).

PFTs were performed according to American Thoracic Society guidelines (19). The following parameters were examined in all patients: partial arterial $\mathrm{O}_{2}$ pressure $\left(\mathrm{PaO}_{2}\right)$ was determined using a Radiometer $\mathrm{Abl} 520$ gas analyzer (Diamond Diagnostic, USA) and expressed in $\mathrm{mmHg}$; forced vital capacity (FVC) was determined using a Morgan Transflow 544 pneumotachograph (Morgan Scientific, USA); and diffusing capacity of the lung for carbon monoxide (DLCO) was determined using the single breath method, with correction for hemoglobin values. FVC and DLCO were expressed as percentages of the predicted normal values (20).

The ${ }^{99 m}$ Tc-DTPA scans were performed by administering the radionuclide as an aerosol from an Ultravent nebulizer (Mallinckdrot Medical Inc, USA) consisting of particles $0.89 \mu \mathrm{m}$ in diameter. Scintigraphy was performed with a gammacamera, equipped with a low energy general purpose collimator interfaced
TABLE 2

Pulmonary function studies and radiographic extent of idiopathic pulmonary fibrosis at diagnosis (TO) and follow-up (T1) in patients with markedly accelerated clearance $(\mathrm{Cl})$ of inhaled technetium-99m diethylenetriaminepentaacetate ( ${ }^{99 m}$ Tc-DTPA) (group I) and patients with moderately accelerated $\mathrm{Cl}$ of inhaled ${ }^{99 \mathrm{~m} T c-D T P A}$ (group II)

\begin{tabular}{|c|c|c|}
\hline TO & $\begin{array}{c}\text { Group I } \\
(\mathrm{Cl}<25 \text { min; } n=10)\end{array}$ & $\begin{array}{c}\text { Group II } \\
(\mathrm{Cl}>25 \text { min; } n=12)\end{array}$ \\
\hline HRCT scan score (\%) & $48.7 \pm 13.3$ & $44.9 \pm 14.0$ \\
\hline FVC (\% pred) & $67.8 \pm 20.6$ & $69.8 \pm 18.3$ \\
\hline DLCO (\% pred) & $38.1 \pm 18.8$ & $35.4 \pm 24.8$ \\
\hline $\mathrm{PaO}_{2}(\mathrm{mmHg})$ & $76.9 \pm 10.3$ & $73.2 \pm 17.8$ \\
\hline \multicolumn{3}{|l|}{$\mathrm{T} 1$} \\
\hline HRCT scan score (\%) & $53.7 \pm 11.7$ & $49.6 \pm 13.0$ \\
\hline FVC (\% pred) & $62.3 \pm 13.2$ & $65.5 \pm 19.3$ \\
\hline DLCO (\% pred) & $24.8 \pm 14.1$ & $30.3 \pm 23.2$ \\
\hline $\mathrm{PaO}_{2}(\mathrm{mmHg})$ & $66.5 \pm 15.6$ & $70.1 \pm 13.1$ \\
\hline
\end{tabular}

Comparison of the two groups (Student's t test for independent variables) showed no significant differences at TO or T1). DLCO Diffusing capacity of the lung for carbon monoxide; FVC Forced vital capacity; HRCT High resolution computed tomography; $\mathrm{PaO}_{2}$ Arterial $\mathrm{O}_{2}$ pressure at rest; pred Predicted normal value

to a computer. Patients were administered the aerosol for 3 min to $4 \mathrm{~min}$ in a closed circuit system and at normal tidal volume. At the end of aerosol administration, chest images were immediately recorded with the patient in the seated position. Each dynamic image was acquired for $10 \mathrm{~s}$ in posterior projection on a $64 \times 64$ matrix, with a total acquisition time of $20 \mathrm{~min}$. Regions of interest were manually drawn around each lung and data were processed to obtain time-activity curves. Clearance half-time was calculated using a least squares curve fitting routine to find the best exponential fit for the first $7 \mathrm{~min}$ of data because the contribution of background activity was insignificant in this time interval. A clearance half-time less than $50 \mathrm{~min}$ was considered to be pathological.

Differences between T0 and T1 findings were investigated using the Student's $t$ test for dependent variables, while the Student's $t$ test for independent variables was used to compare the findings between different groups. Correlations among HRCT scores, pulmonary function studies and ${ }^{99 \mathrm{~m}} \mathrm{Tc}$-DTPA clearance were analyzed using the two-tailed Pearson's correlation coefficient. $\mathrm{P}<0.05$ was regarded as significant.

\section{RESULTS AND DISCUSSION}

At presentation (TO), irregular opacities, prevailing at the bases, were observed in all patients' chest radiographs. All patients showed a restrictive ventilatory impairment (Table 1). DLCO values correlated significantly with both $\mathrm{PaO}_{2}(\mathrm{r}=0.53$, $\mathrm{P}=0.021)$ and FVC $(\mathrm{r}=0.57, \mathrm{P}=0.009)$ at T0. The extent of parenchymal abnormalities evaluated with HRCT score showed an inverse and significant correlation with $\mathrm{PaO}_{2}$ $(\mathrm{r}=-0.064, \mathrm{P}=0.001)$, FVC $(\mathrm{r}=-0.047, \mathrm{P}=0.023)$ and DLCO $(\mathrm{r}=-0.046, \mathrm{P}=0.028)$ at T0. Clearance of ${ }^{99 \mathrm{~m}} \mathrm{Tc}-\mathrm{DTPA}$ did not show any significant relationship with the other parameters considered, at either T0 or T1.

The extent of the lesions demonstrated by HRCT scan showed a significant increase during the TO to T1 interval; similarly, a significant decrease in FVC, DLCO and $\mathrm{PaO}_{2}$ was observed. A decrease in the extent of reticular opacities was 
not observed in any patient. On the other hand, the clearance of inhaled ${ }^{99 \mathrm{~m}}$ Tc-DTPA showed a significant slowing during the T0 to T1 interval (higher and therefore less pathological values of half-time) (Table 1).

Clearance of inhaled ${ }^{99 \mathrm{~m}}$ Tc-DTPA was less than $50 \mathrm{~min}$ in all patients at T0. To investigate whether ${ }^{99 \mathrm{~m}} \mathrm{Tc}$-DTPA clearance at presentation could be considered a predictive index of clinical course, the patients were subdivided into two groups: patients with a half-time clearance less than 25 min at TO (group I, n=10) and patients with a half-time clearance greater than $25 \mathrm{~min}$ at T0 (group II, $\mathrm{n}=12$ ). Comparing the two groups at T0, PFTs and HRCT scores showed no significant differences (Table 2).

During the T0 toT1 interval, a worsening of both radiological and functional parameters was observed in both groups I and II, although in patients with half-time clearance less than 25 min (group I), only DLCO and $\mathrm{PaO}_{2}$ changes were statistically significant. In patients with a half-time clearance greater than 25 min (group II), all parameter changes were significant. Further, at T1 there were no significant differences between the two groups (Table 2). Therefore, the evolution of impairment was very similar between the two groups.

No correlations were found between ${ }^{99 \mathrm{~m}} \mathrm{Tc}$-DTPA clearance and PFTs or HRCT quantitative scores at baseline, and changes in HRCT and PFTs were not correlated with changes in ${ }^{99 \mathrm{~m}} \mathrm{Tc}$-DTPA clearance values. Patients with more rapid clearance at presentation did not show more functional or radiological deterioration. In fact, clearance tended to improve, while the other indexes worsened.

These results were not influenced by treatment because no significant difference, in any considered parameter, was observed

\section{REFERENCES}

1. Katzenstein ALA, Myers JL. Idiopathic pulmonary fibrosis: Clinical relevance of pathologic classification. Am J Respir Crit Care Med 1998;157:1301-15.

2. American Thoracic Society/European Respiratory Society International Multidisciplinary Consensus Classification of the Idiopathic Interstitial Pneumonias. Am J Respir Crit Care Med 2002;165:277-304.

3. Flaherty KR, Mumford JA, Murray S, et al. Prognostic implications of physiologic and radiographic changes in idiopathic interstitial pneumonia. Am J Respir Crit Care Med 2003;168:543-8.

4. Latsi P, Du Bois R, Nicholson A, et al. Fibrotic idiopathic interstitial pneumonia. The prognostic value of longitudinal trends. Am J Respir Crit Care Med 2003;168:531-7.

5. Collard HR, King TE Jr, Bartelson BB, Vourlekis JS, Schwarz MI, Brown KK. Changes in clinical and physiologic variables predict survival in idiopathic pulmonary fibrosis. Am J Respir Crit Care Med 2003;168:538-42.

6. American Thoracic Society. Idiopathic pulmonary fibrosis: Diagnosis and treatment. International consensus statement. American Thoracic Society (ATS) and European Respiratory Society (ERS). Am J Respir Crit Care Med 2000;161:646-64

7. Mason GR, Uszler JM, Effros RM, Reid E. Rapidly reversible alteration of pulmonary epithlial permeability induced by smoking. Chest 1983;83:6-11.

8. Jones JG, Minty BD, Lawler P, Hulands G, Crowley JCQ, Veall N. Increased alveolar permeability in cigarette smokers. Lancet 1980;8:66-80.

9. Kennedy SM, Elwood RK, Wiggs BJR, Pare PD, Hogg JC. Increased airway mucosal permeability of smokers. Relationship to airway reactivity. Am Rev Respir Dis 1984;129:143-8.

10. Fanti S, De Fabritiis A, Aloisi D, et al. Early pulmonary involvement in systemic sclerosis assessed by technetium 99m_DTPA clearance rate. J Nucl Med 1994;35:1933-6. between treated and untreated subjects, either at T0 or at T1 (data not shown).

Previous studies have investigated the role of ${ }^{99 m}$ Tc-DTPA scans in the management of IPF patients; according to some authors (14), a normal ${ }^{99 \mathrm{~m}}$ Tc-DTPA clearance at presentation may predict stable lung function, while accelerated clearance may identify those cases that will further progress. However, this study included a majority of patients with idiopathic interstitial pneumonias other than IPF.

Recently, Mogulkoc et al (15) analyzed the ${ }^{99 \mathrm{~m} T c-D T P A}$ clearance in a considerable number of patients with significant ground-glass opacities in the HRCT scan, thought to represent IPF at an early stage. The authors identified ${ }^{99 m}$ Tc-DTPA clearance as an independent predictor of survival, together with age, total lung capacity and DLCO (15). However, clearance was the least significant among the parameters considered, and did not correlate with PFTs or HRCT scores (15). A prognostic role cannot be excluded, especially when the diagnosis of IPF is early; however, at present, these results may not justify the use of an expensive and time-consuming technique such as ${ }^{99 \mathrm{~m}} \mathrm{Tc}$-DTPA scans.

\section{CONCLUSIONS}

Although the small number of patients considered precludes any definitive conclusion, our results suggest that ${ }^{99 \mathrm{~m}} \mathrm{Tc}$-DTPA scans may be too expensive when compared with the information supplied by other, less costly techniques. We conclude that the use of ${ }^{99} \mathrm{~m}$ Tc-DTPA scan is not of value in following the progress of IPF, due to its poor predictive value on the clinical course of this disease.

11. Mason GR, Peters AM, Bagdades E, Myers MJ, Snook D, Hughes JM. Evaluation of pulmonary alveolar epithelial integrity by the detection of restriction to diffusion of hydrophilic solutes of different molecular sizes. Clin Sci 2001;100:231-6.

12. Rinderknecht J, Shapiro L, Krauthammer M, et al. Accelerated clearance of small solutes from the lungs in interstitial lung disease. Am Rev Respir Dis 1980;121:105-17.

13. British Thoracic Society, Standards of Care Committee. The diagnosis, assessment and treatment of diffuse parenchymal lung disease in adults. Thorax 1999;54(Suppl 1):S1-28.

14. Wells AU, Hansell DM, Harrison NK, Lawrence R, Black CM, du Bois RM. Clearance of inhaled Tc-99m-DTPA predicts the clinical course of fibrosing alveolitis. Eur Resp J 1993;6:797-802.

15. Mogulkoc N, Brutsche MH, Bishop PW, et al. Pulmonary 99mTc-DTPA aerosol clearance and survival in usual interstitial pneumonia (UIP). Thorax 2001;56:916-23.

16. Wells AU, Hansell DM, Rubens MB, Cullinan P, Black CM, du Bois RM. The predictive value of appearance on thin-section computed tomography in fibrosing alveolitis. Am Rev Respir Dis 1993;148:1076-82.

17. McGuinness G. High-resolution computed tomography: Technique and pitfalls. Semin Roentgenol 2002;37:5-16.

18. Battista G, Zompatori M, Fasano L, Pacilli A, Basile B. Progressive worsening of idiopathic pulmonary fibrosis. High resolution computed tomography (HRCT) study with functional correlations. Radiol Med (Torino) 2003;105:2-11.

19. American Thoracic Society. Standardization of spirometry, 1994 update. Am J Respir Crit Care Med 1995;152:1107-36.

20. Quanier PH, ed. Standardized lung function testing. Report Working Party Standardization of Lung Function Tests, European Community for Coal and Steel. Eur Respir J 1993;6(Suppl 16):1-100. 


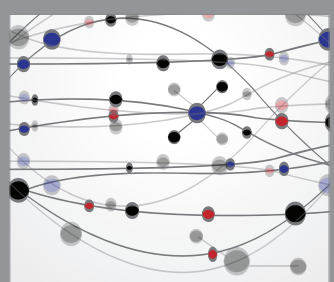

The Scientific World Journal
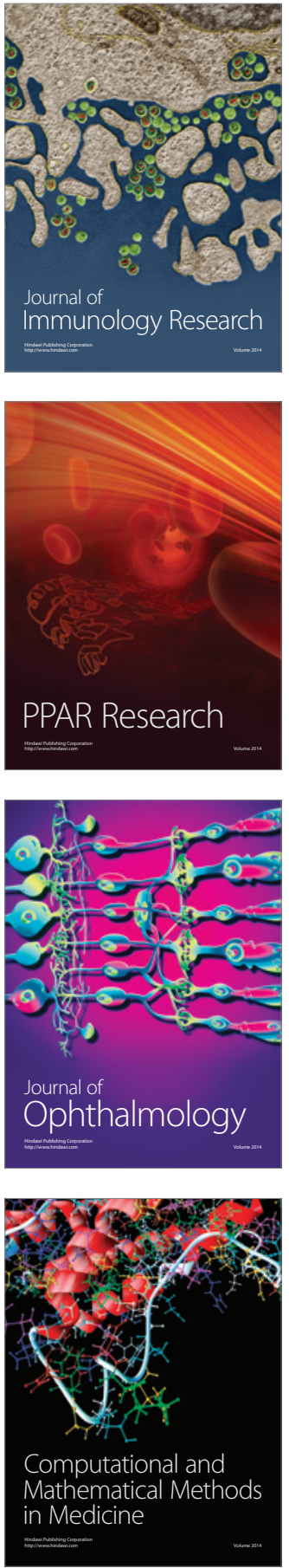

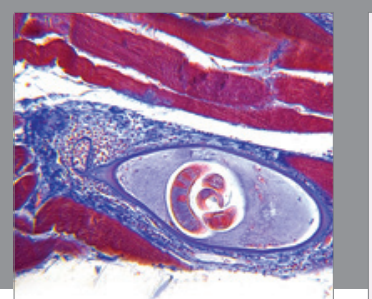

Gastroenterology Research and Practice

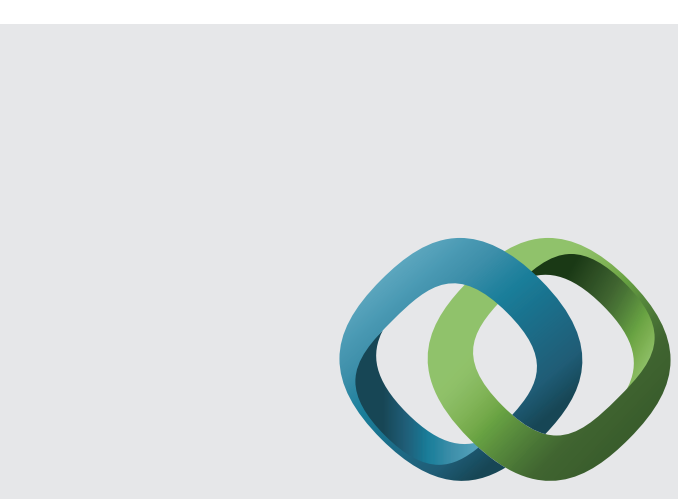

\section{Hindawi}

Submit your manuscripts at

http://www.hindawi.com
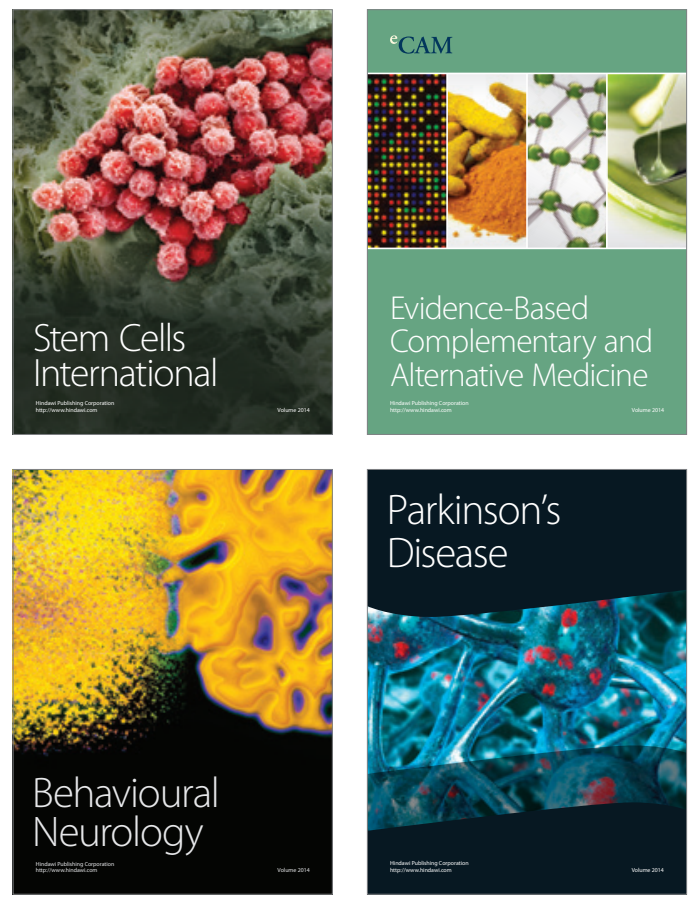
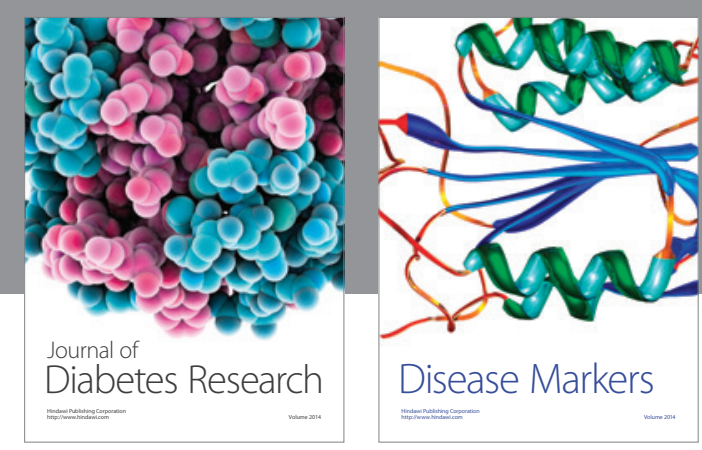

Disease Markers
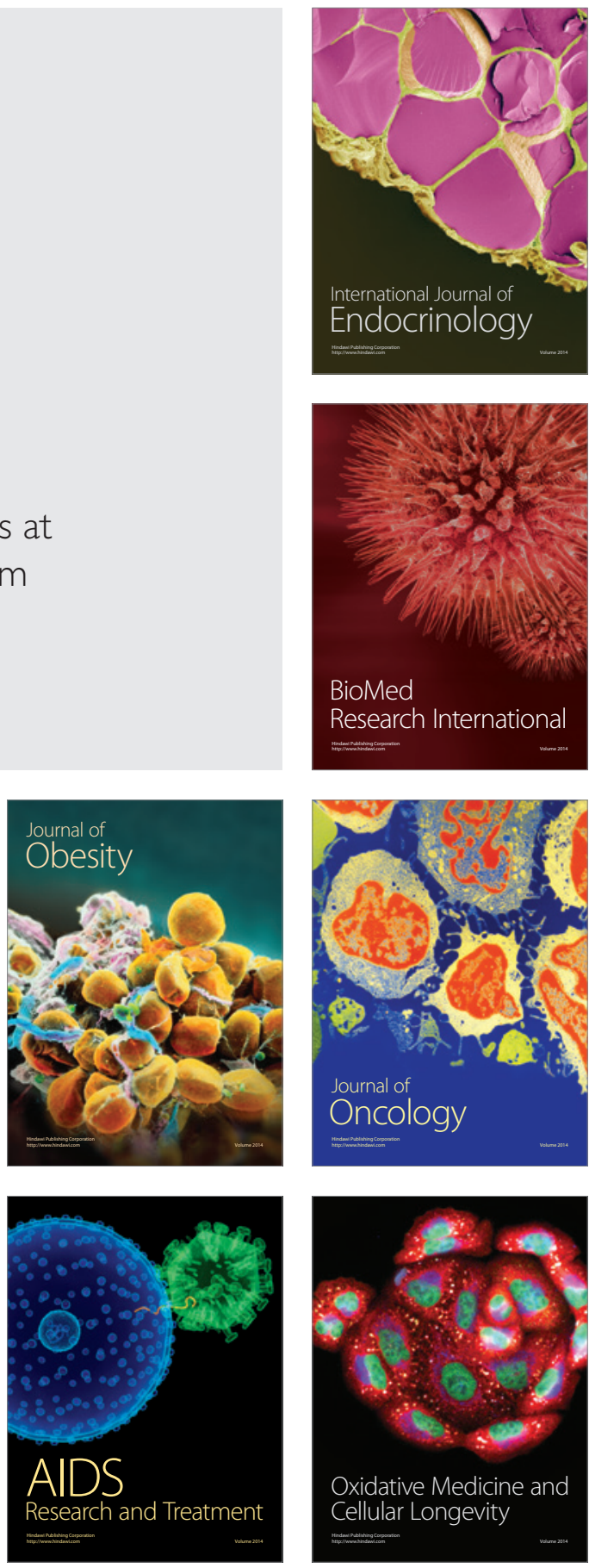